\title{
EDITORIAL CONVENTIONS
}

Throughout this study several conventions have been employed. Although Luso-Brazilian orthography seems endlessly in flux, I have tried to follow modern Portuguese preferences with respect to accents and the spelling of names and terms wherever possible. Foreign terms are italicized only when first introduced. From 1580 to 1640 Portugal and its empire was ruled by three Spanish sovereigns - Philip II, III, and IV; I have used those designations, which are more common than the Portuguese alternatives-Philip I, II, and III. All units of weight, dry measures, and length are expressed in metric terms; for example, the standard Portuguese arroba $(32 \mathrm{lb}$.) is I 4.5 kilograms, and I mile is I. 6 kilometers. To present monetary data uniformly, I have converted the several forms of money or money of account employed in the lands east of the Cape of Good Hope into their equivalents in Portugal and its Atlantic empire. For details, consult Appendix A. The Gregorian Calendar was accepted by Portugal and other Catholic lands in 1582 but was resisted by England until I752, when 3 September suddenly became I4 September. Until then, the Portuguese New Year began on I January, but for the English the year changed on 25 March. Before 1752, English consular and diplomatic officials sometimes adhered to what was termed Old Style (OS) dating and sometimes employed New Style (NS). In the notes I have generally followed the dispatch writer's preference but, where necessary, have adjusted the dates to be consistent with Portuguese practice. Unless specifically indicated, persons with identical surnames are not known to have been related. 



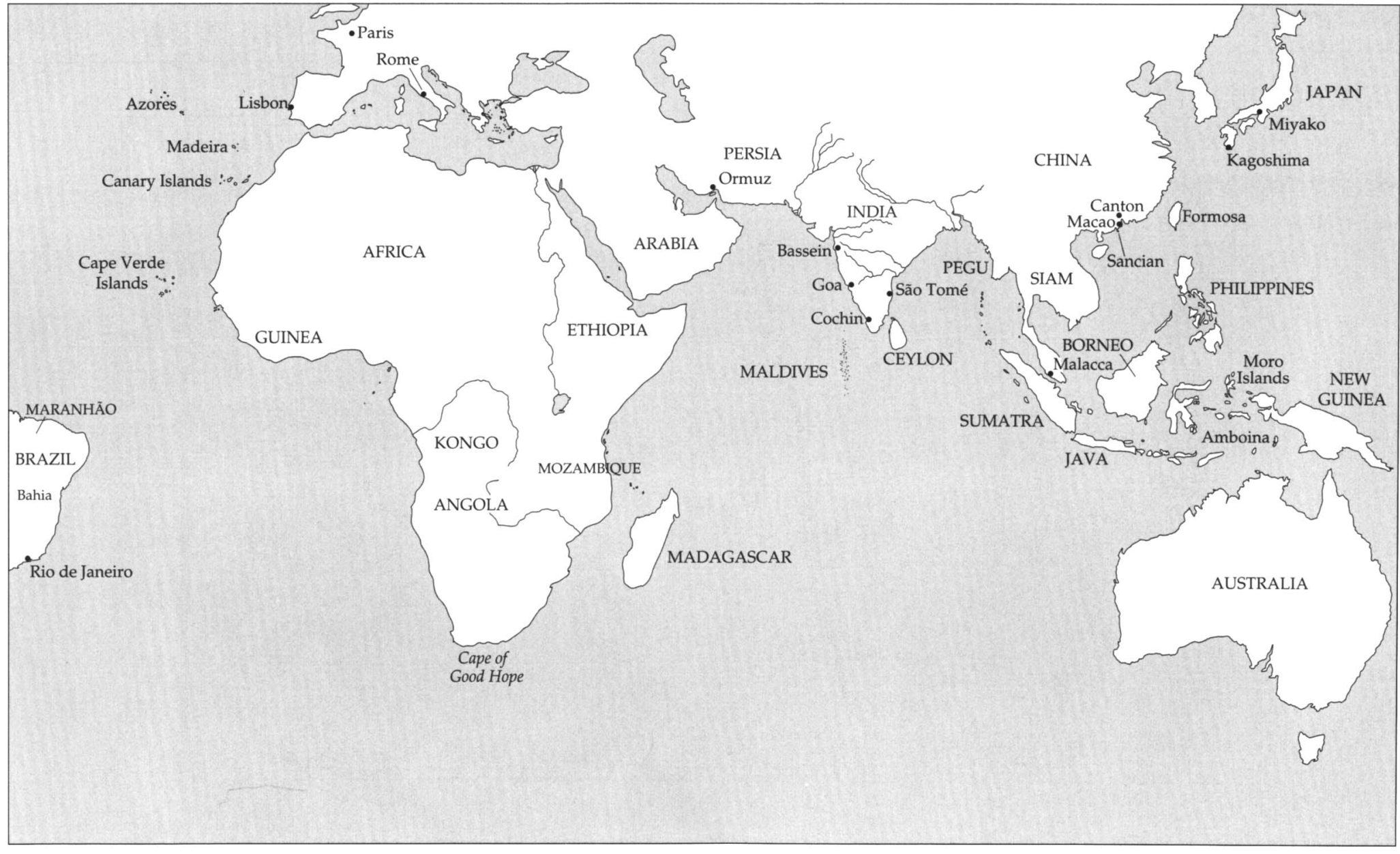

Map 1. The Portuguese Assistancy. 


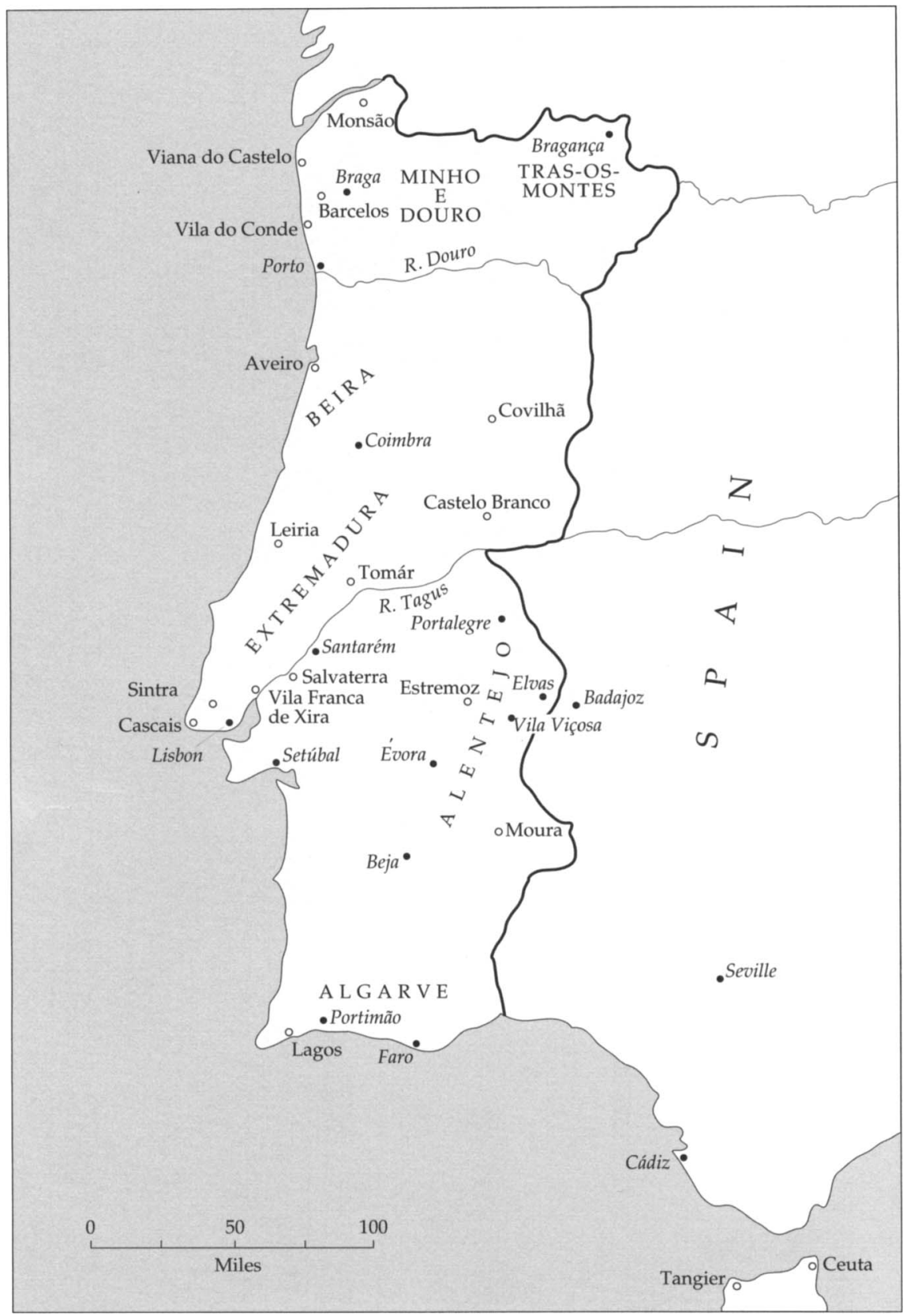

Map 2. Principal Jesuit installations in and near Portugal. Italic type indicates Fesuit centers. 


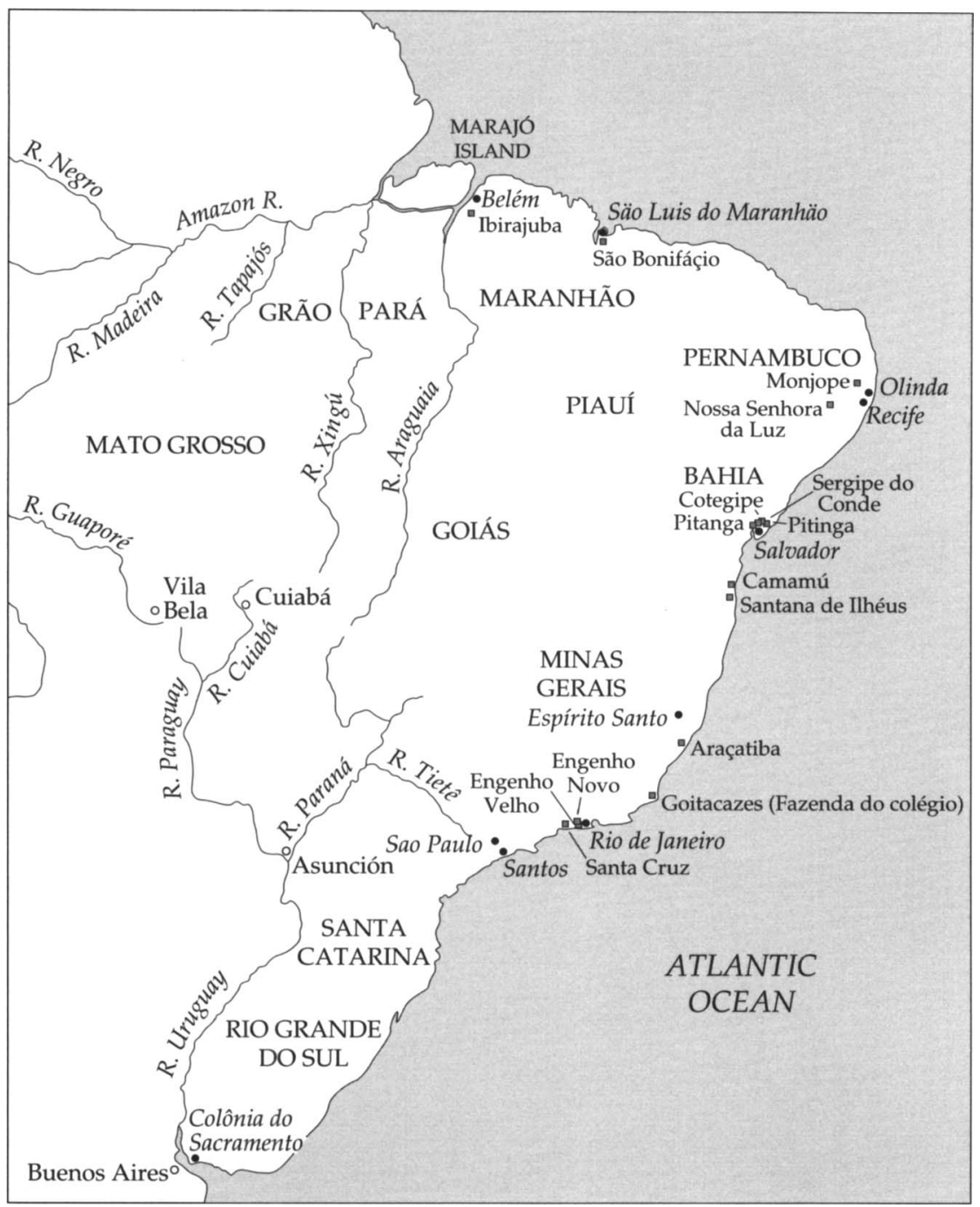

Map 3. Jesuit centers and supporting sugar estates in colonial Brazil. Italic type indicates Fesuit centers. 


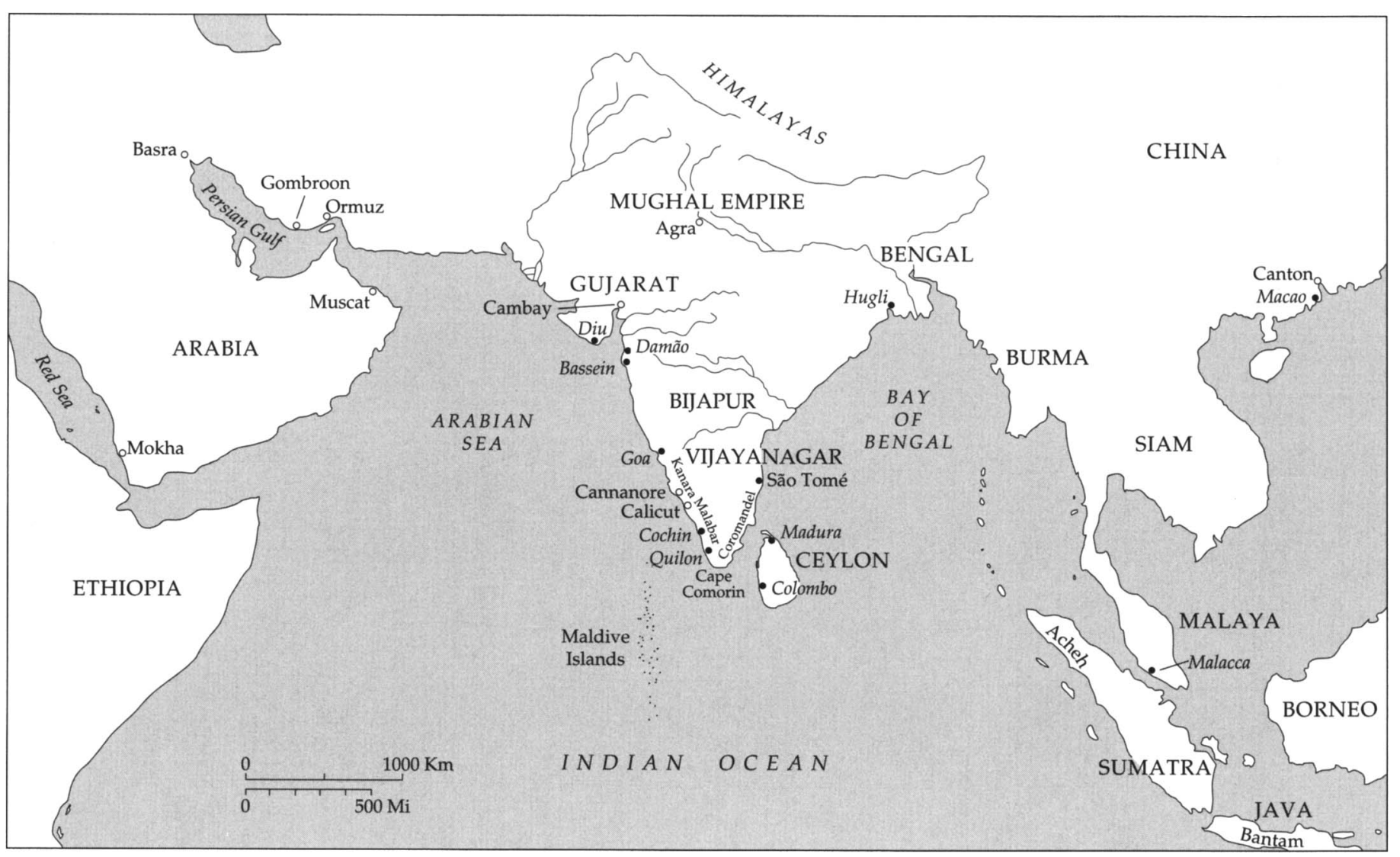

Map 4. The Estado da India. Italic type indicates Fesuit centers. 


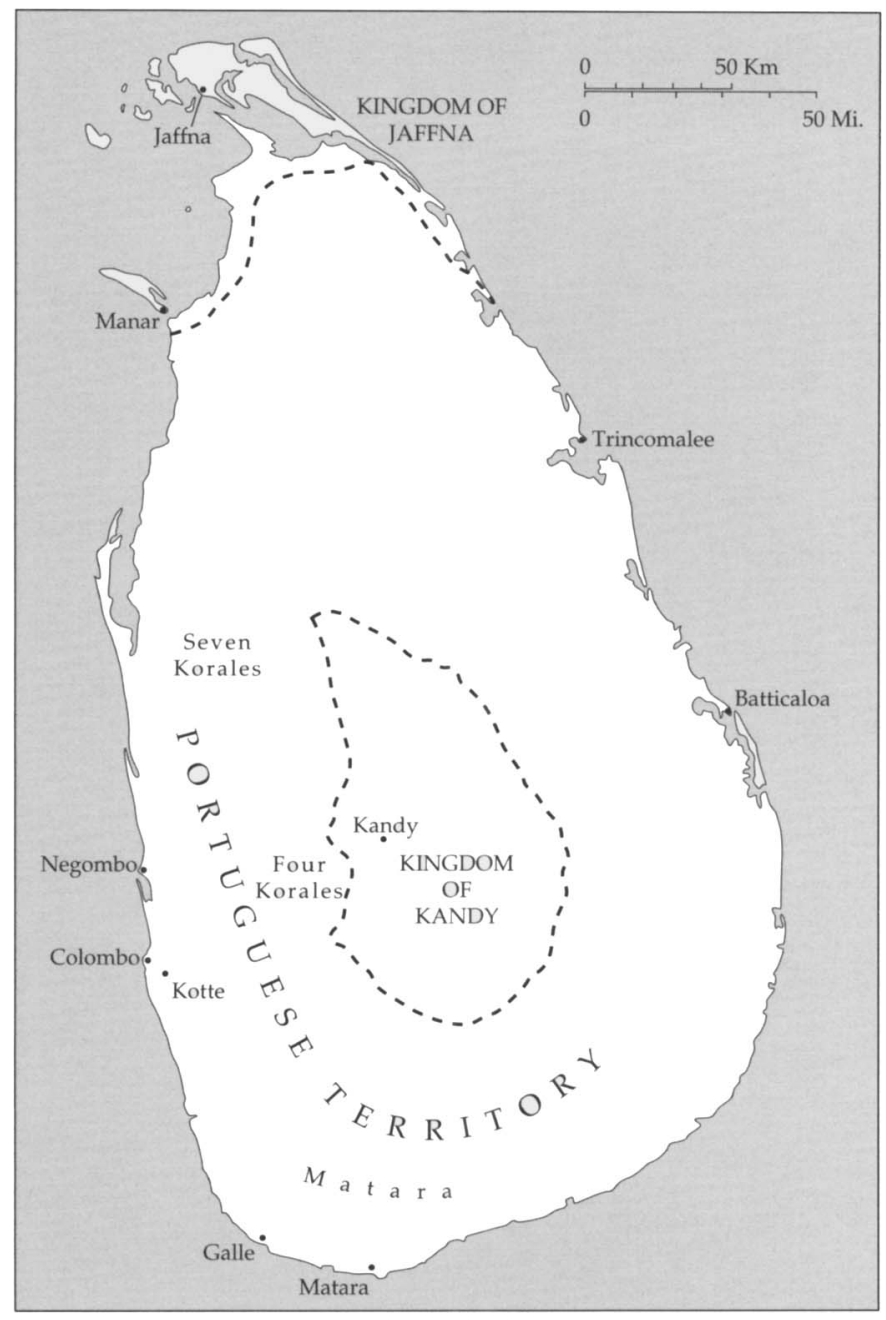

Map 5. Ceylon during the early seventeenth century.

Map 6 (below). The city and territory of Goa to the i74os.

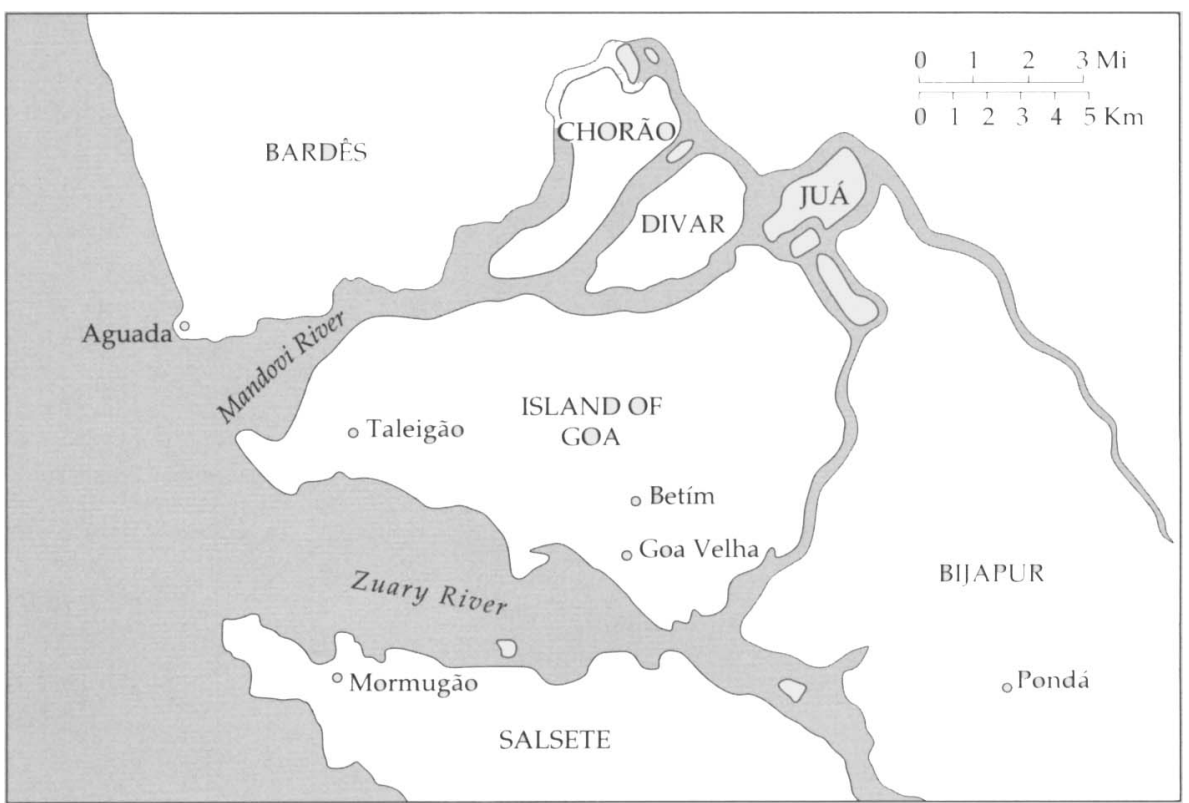




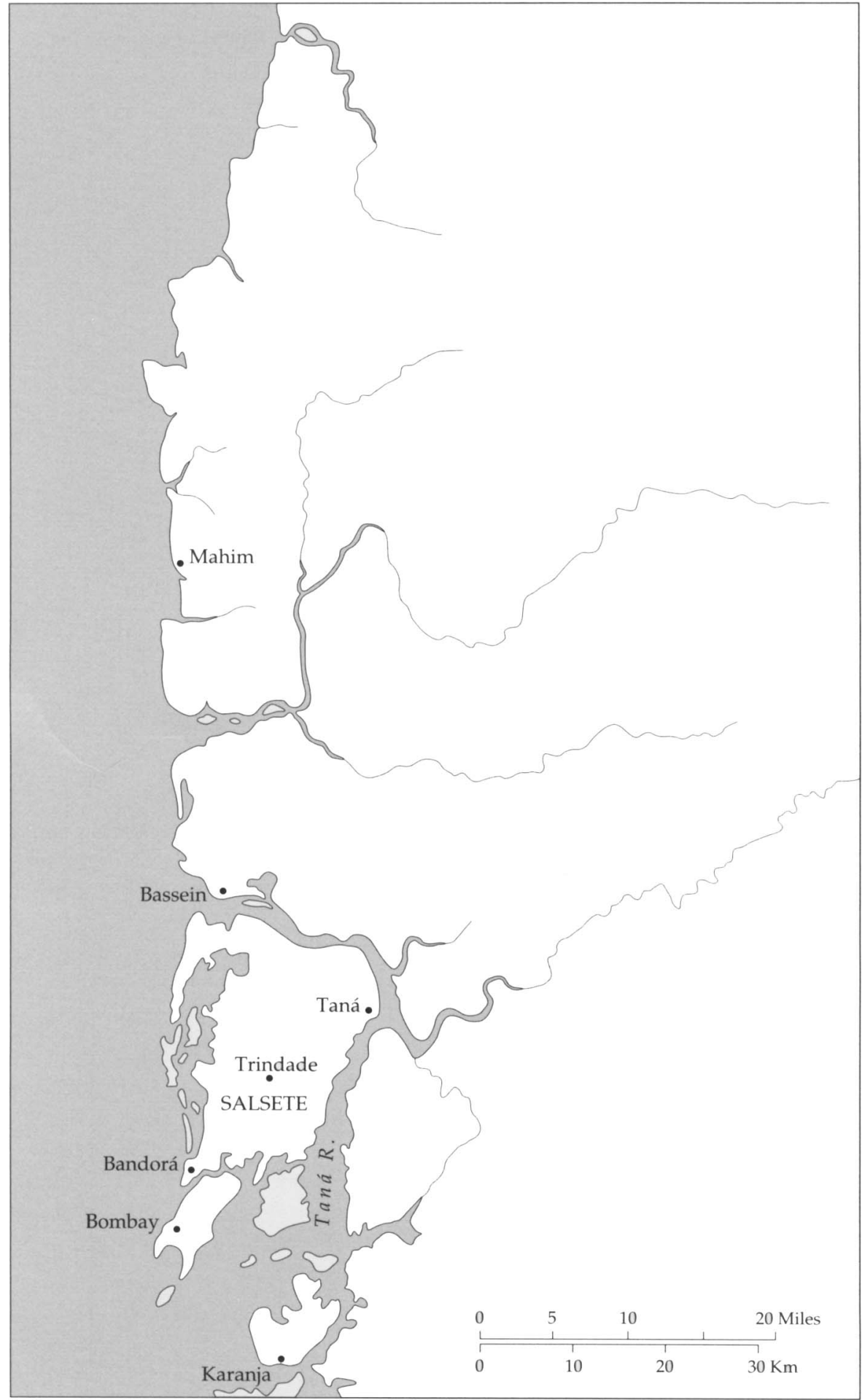

Map 7. Bombay and portions of the northern province. 